AGENDA : Analisis Gender dan Agama , Vol. 3 (1), 2021, (Juni) ISSN Print: 2615-1502

ISSN Online: $\underline{2723-3278}$

Tersedia online di

\title{
UNDERSTANDING OF THE LINTANG TRIBE SOCIETY ABOUT WOMEN WHO ARE HARAM TO BE MARRIED ON ISLAMIC LAW PERSPECTIVE
}

\author{
Zurifah Nurdin \\ IAIN Bengkulu \\ E-mail : zurifah@iainbengkulu.ac.id
}

\begin{abstract}
This study aims to determine the women who are haram to marry and why it is haram to marry and how to analyze Islamic law on women who are haram to marry on the understanding of the Lintang tribe community. The research results are described and then analyzed how the views and thoughts of Islamic law. The majority of the Lintang are Muslim, who adhere to the traditional Nahdhatul Ulama understanding and are patrilineal. According to their understanding that cousins, especially aunt's daughters from the father's side and the uncles' daughters from the mother's side, are women who are forbidden to marry, even though in some literature the cousins of Fiqh, aunt's daughters and uncle's daughters, both mother and father, can be married. This prohibition is to maintain the harmony of the guardianship system in patrilineal kinship. For the people of the Lintang tribe, marrying such a cousin is an act of nula and taboo / violates custom ethics. based on the principle of 'urf, maslahah mursalah and sadd-adzari'ah prohibition of marrying a cousin as the understanding of the Lintang tribe does not conflict with maqashid syri'ah so that it needs to be preserved and is part of Islam Nusantara.
\end{abstract}

Keywords: Women, Marriage, Haram, Islam

PENDAHULUAN:

Suku Lintang mendiami wilayah kecamatan Muara Pinang dan kecamatan Pendopo, Suku ini termasuk dalam rumpun Deutro Melayu, yang hidup berdampingan dengan suku Pasemah dan Rejang. ${ }^{1}$ Suku Lintang

1 Www. Wacananusantara.org/suku Lintang. di akses 2 Mei 2019, jam 18.00 menganut sistem kekeluargaan patrilineal. Kepemimpinan kaum pria ini sudah melekat kuat dalam masyarakat suku Lintang.. Sistem perkawinan menganut sistem jujur, laki-laki yang memberi mahar dan uang hantaran, laki-laki yang melamar, bertanggung jawab terhadap keperluan hidup atau nafkah keluarga, berhak 
menjadi wali dan semua keputusan ada ditangan kaum laki-laki. ${ }^{2}$ kaum lakilaki wajib dihormati, karena kedudukannya yang sangat mulia dan tinggi. Seluruh masyarakat suku Lintang beragama Islam yang sangat taat sehingga sering disebut sosokan Mekkah, setiap malam terdengar anakanak mengaji di rumah-rumah guru mengaji yang hanya berjarak $250 \mathrm{~m}$ saja, setiap malam jum'at selalu ada pembelajaran marhaban sedang siang harinya ibu-ibu dan bapak-bapak mengaji kitab-kitab fiqh, tsawuf dan lain sebagainya.

Beradasarkan pengamatan awal di dapatkan fakta bahwa pemahaman masyarakat suku Lintang tentang perempuan yang haram dinikahi itu untuk selamanya anak perempuan sekandung, sebapak, seibu, ibu, istri dari bapak, saudara tiri, saudara sepupuh : anak perempuan dari bibi pihak ayah dan anak perempuan dari paman pihak ibu, sedangkan anak perempuan dari paman pihak ayah dan anak perempuan dari bibik pihak ibu boleh dinikahi. Sedangkan dalam teori hukum Islam/fiqh sebagaimana dijelaskan oleh Wahbah az Zuhaili ${ }^{3}$ bahwa perempuan yang diharamkan diniakhi karena hubungan darah adalah orang tua, baik ibu maupun nenek, Anak yakni anak perempuan, cucu perempuan dan cucu buyut. Lalu Anak orang tua, yang termasuk dalam golongan ini adalah baik saudara perempuan sekandung, sebapak

2 Hasil wawancara dengan Orang yang dituakan yakni dengan bapak KH. Husen 70 tahun, ketua Adat bapak Romli 68 tahun, sesepuh masyarakat yakni H. Fikri 68 tahun, Hj Sot 80 tahun dan Hj Faridah 67 tahun, pada tanggal 09 Nopember 2019 dan juga dari hasil pengamatan peneliti.

3 Wahbah az Zuhaili, al Fiqh al Islamy., Op., Cit 126. maupun seibu, anak perempuan dari saudara laki-laki dan saudara perempuan walaupun diurutan buyut serta bibi dari pihak bapak dan ibu. Sedangkan anak perempuan dari bibi dan paman baik dari bapak (sepupu), dan ataupun dari pihak ibu di bolehkan untuk dinikahi.

Dari sini jelas ada perbedaan, dalam Fiqh sepupuh perempuan yakni anak dari bibi dan ataupun paman dari pihak ayah maupun pihak ibu boleh dinikahi sedangkan dalam pemahaman masyarakat suku Lintang menikahi sepupuh perempuan, yakni anak perempuan paman dari pihak ibu dan anak perempuan bibik dari ayah itu haram dinikahi. Oleh karena itu penulis ingin menuangkan hasil penelitian tersebut dalam tulisan yang berjudul pemahaman masyarakat suku Lintang tentang perempuan yang haram dinikahi persepektif hukum Islam

a. Penelitian Terdahulu

Penelitian sebelumnya telah banyak membahas masalah perempuan yang haram dinikahi namun berbeda masalalah yang diteliti. Perbedaannya nampak pada pokok masalah dalam tulisan ini penulis pokus pada stutus hukum menikahi sepupuh yakni anak perempuan bibi dari bapak dan anak paman dari ibu bagi masyarakar Lintang sedangkan penelitian lain masih umum, seperti dalam tulisan Al Farisi bahwa perempuan yang haram dinikahi adalah Ibu, Nenek, Anak, cucu, dan Saudara kandung atau sebapak atau seibu. Keponakan, bibi dari bapak atau ibu merupakan perempuan yang diharamkan 
dinikahi selama-lamanya. ${ }^{4}$ Agus Hermanto menjelaskan bahwa seorang laki-laki haram menikahi perempuan yang senasab, ada hubungan perkawinan dengan yang lain dan karena satu ibu susu ${ }^{5}$ adapun yang termasuk senasab Ibu kandung, nenek, Anak, cucu baik dari anak laki-laki maupun perempuan, saudara perempuan, baik seayah seibu, seayah saja, atau seibu saja, bibi saudara perempuan ayah atau ibu, baik saudara sekandung ayah atau ibu keponakan perempuan; anak perempuan paman atau bibi dari pihak ayah maupun ibu.

Lalu dalam artikel yang ditulis oleh Zurifah Nurdin dinyatakan bahwa dalam memilih perempuan untuk dinikahi itu harus teliti jangan sampai menikahi perempuan yang diharamkan oleh agama, perempuan yang haram dinikahi itu diantaranya adalah bibik, saudara sekandung, saudara sebapak, ponaan dan cucu. ${ }^{6}$ Kemudian penelitian yang berjudul Analisis Komparasi Tentang Larangan Pernikahan Dalam Hukum Islam dan Hindu, dinyatakan bahwa dalam hukum Islam pengharaman menikahi perempuan ada yang selamanya dan ada sementara

4 http://alfarisi.web.id/articles/yang-haramdinikahi-untuk-selamanya/

5 file://C:/Users/user/Downloads/1049-2267-

1-SM.pdf. Agus Hermanto

jurnal+iain+ponorogo\&aq Muslim Heritage,

Vol. 2, No.1, Mei - Oktober 2017

6https://ejournal.iainbengkulu.ac.id/index. php/syiar/article/view/910. Zurifah

Nurdin, Etika Mencari Pendamping Hidup

Menurut Islam, Jurnal Ilmiah Syi'ar, 2017,

Vol. 17, hl 107-118 sedangkan dalam agama Hindu pengharamannya dikarenakan oleh pelaku itu sendiri, terkait kasta. ${ }^{7}$ Dan ada juga yang menyatakan bahwa pengharaman itu bisa dikarenan hubungan darah dan bisa juga disebabkan yang lainnya. ${ }^{8}$ Sementara Abdullah bin Abdurrahman bin Shalih Ali Bassam menyatakan bahwa perempuan itu ada yang dilarang dinikahi selama-lamanya, dan ada yang dilarang hanya hingga berbatas waktu dan haram karena hubungan perbesanan. ${ }^{9}$ Dengan demikian jelas bahwa tulisan penulis ini sangat berbeda dengan fokus tulisan penulis yang lain. Para penulis terdahulu menjelaskan secara umum perempuanperempuan yang haram dinikahi sedangkan penulis dalam tulisan hanya menelaah keharaman menikahi sepupuh yang dilahirkan dari bibi pihak ayah dan paman dari ibu.

b. Rumusan Masalah

Rumusan masalah dalam penelitian adalah kenapa sepupuh perempuan; anak bibi dari pihak ayah dan anak paman dari pihak ibu haram dinikahi dan bagaimana analisa hukum Islam terhadap pengaharaman menikahi sepupuh (anak paman dari ibu dan anak bibi dari ayah) sebagaimana pemahaman masyarakat suku Lintang.

7 Ahmad Zainul Wafa AL-HUKAMA The Indonesian Journal of Islamic Family Law Volume 01, Nomor 01, Juni 2011; ISSN:2089-7480

8 http://etheses.uinmalang.ac.id/1690/6/03210037

9 https://almanhaj.or.id/1741-wanitawanita-yang-dilarang-dinikahi.html Syaikh Abdullah bin Abdurrahman bin Shalih Ali Bassam 
c. Kerangkan Teori

Dalam Islam perempuan itu ada yang boleh untuk dinikahi dan adapula yang haram. Untuk Perempuan yang haram dinikahi itu ada yang haram selamanya (abadi) ada pula yang haram sementara (temporal). Pengharaman itu disebabkan hubungan nasab, besanan atau susuan. Perempuan yang haram dinikahi selamanya ada dua puluh lima sedangkan karena hubungan pebesanan ada empat dan perempuan yang haram dinikahi sementara ada dua puluh tiga perempuan. ${ }^{10}$ Karena hubungan nasab, menyebabkan pernikahan haram selamanya. Yang termasuk kedalam golongan ini adalah Ibu, nenek dan garis keturunan keatas. Anak, cucu, cicit. Saudaa sekandung, sebapak dan seibu, bibik baik baik dari bapak maupun dari ibu sekandung, sebapak atau seibu. Ponaan dari saudara laki-laki dan atapun saudara perempuan, anak ponaan baik sekandung, sebapak atau seibu. ${ }^{11}$

Pengharaman nenek untuk dinikahi berbadasarkan nash baik nash al Qur'an dan al Hadis. ${ }^{12} \mathrm{Cucu}$ perempuan demikan juga sebab cucu kekerabatannya sangat dekat kepada ibu dari pada bibi dan secara metafora cucu itu dianggap sebagai anak. $^{13} \quad$ Wahbah az Zuhaili $^{14}$ perempuan yang haram dinikahi selamnya itu adalah ibu, nenek,

10 Ibnu Rusyd, Bidayatul Mujtahid, Op. Cit., 13-34, 39-49,57-59. Al Qur'an surat an Nisa'; $22-24$

11 Q.S An Nisa' 23

12 Dalalah An Nash, al-Qu'an dan Hadis

13 Abu Zahra, Op., Cit, 48

14 Wahbah az Zuhaili, al Fiqh al Islamy., Op., Cit 126. anak, cucu, cucu buyut. anak orang tua sekandung, seibu, sebapak, Ponaan baik dari saudara perempuan maupun dari saudara laki-laki. Bibi dari pihak bapak dan ibu. Sedangkan sepupuh yakni anak bibi dan paman dari pihak bapak atau pihak ibu dihalalkan untuk dinikahi berdasarkan Nash ${ }^{15}$

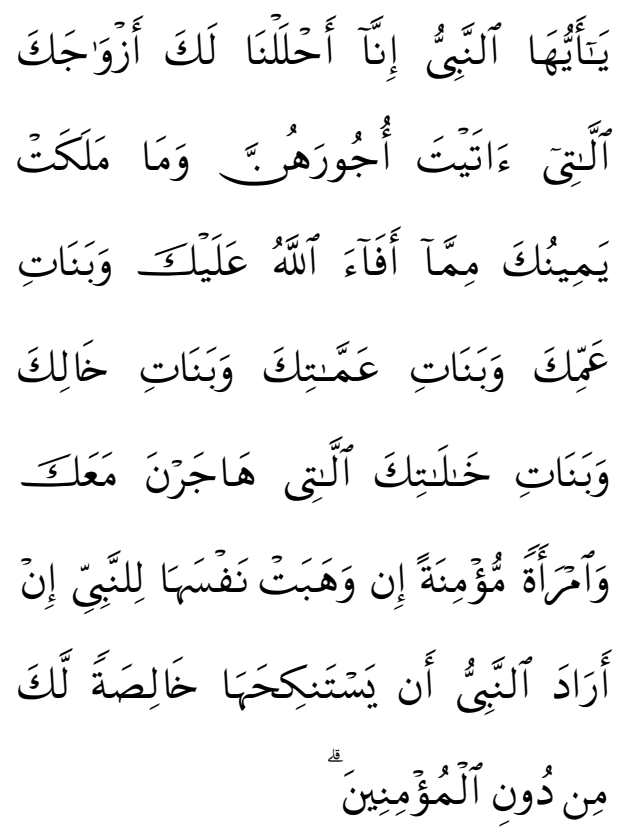

Hai Nabi, Sesungguhnya Kami telah menghalalkan bagimu isteriisterimu yang telah kamu berikan mas kawinnya dan hamba sahaya yang kamu miliki yang Termasuk apa yang kamu peroleh dalam peperangan yang dikaruniakan Allah untukmu, dan demikian pula anak-anak perempuan dari saudara laki-laki bapakmu, anak-anak perempuan dari saudara perempuan bapakmu, anak-anak perempuan dari saudara laki-laki ibumu dan anak-anak perempuan dari saudara perempuan ibumu yang turut hijrah bersama kamu dan perempuan mukmin yang menyerahkan dirinya kepada Nabi kalau Nabi mau

15 Al Qur'an surat al Ahzab; 50 
mengawininya, sebagai pengkhususan bagimu, bukan untuk semua orang mukmin.

Pengaharaman ini bertujuan agar sistem kekeluargaan yang dibangun berlandaskan cinta dan kasih sayang yang murni, dan menetralisir putusnya hubungan kekeluargaan akibat terjadinya pererselisihan dalam rumah tangga pasangan suami istri. ${ }^{16}$ Serta menetralisir melahirkan keturunan yang lemah baik mental, maupun jasmani. ${ }^{17}$ Adapun pengharaman menikahi perempuan karena besanan, adalah istri ayah, istri kakek, istri buyut, baik jalur ayah ataupun jalur ibu, bagaimanapun kondisinya. ${ }^{18}$ Menantu (istri anak), cucu menantu (istri cucu), sisi ibu atau ibu, telah disetubuhi atau belum, dan bahkan sudah cerai sekalupun. ${ }^{19}$ Mertua baik kandung, sesusuan, beserta nenek dari bapak dan atau dari ibu,. ${ }^{20}$ Dan anak tiri ${ }^{21}$ pengharaman mereka ini dikatagorikan atau disamakan dengan menyetubuhi perempuan dengan akad yang batal seperti melakukan pernikahan tanpa wali $^{22}$ Sedangkan hubungan susuan itu diharamkan karena disamakan

16 Al Kasani dalam Wahbah az Zuhaili dalam al Fiqh al Islamy,. Op. Cit., h. 127

17 Dalam Atsar dinyatakan" jangan menikahi suadara dekat untuk menghindari keturunan cacat.

18 Al Qur'an : an Nisa';22.

19 Al Qur'an surat an Nisa'; 23. dalam Ayat ini di pahami bahwa istri anak angkat boleh dikawini oleh ayah angkatnya.

20 Dalam Hadis yang diriwayatkan oleh at Turmuzi, dijelaskan bahwa Rasulullah bersabda' tidak boleh mengawini mertua, walau sang istri diceraikan sebelum digauli.

21 baik tinggal serumah atau tidak.

22 Wahbah az Zuhaili, al Fiqh al Islamy..Op., Cit., h. 129-131 dengan senasab, ${ }^{23}$ Dalam Kompilasi Huku Islam pasal 39-44, perempuan yang haram dinikahi adalah, ibu kandung, bibik, nenek, mertua, mantan istri yang dicerai sebelum persetubuhan, anak bekas istri, persesusuan, anak yang menyusu pada istrinya, masih dalam iddah, non muslimraian dala. Uraian perempuan yang haram dinikahi dapat dilihat pada lampiran.$^{24}$

Teori pembahas yang digunakan untuk mengistinbat hukum dalam masalah menikahi sepupuh perempuan baik anak paman dari pihak ibu maupun anak bibik dari pihak ayah adalah al 'urfu ashahihah, maslahah al mursalah dan sadd adzzari'ah. Kedua teori menurut penulis sangat relevan sebab yang menjadi masalah adalah pemahaman masyarakat suku Lintang yang telah menjadi adat atau kebiasaan dan untuk mengukur apakah kebiasaan itu shahihah maka diperlukan metode maslahah al mursalah khsususnya maslahah adhoruriyah. Kebiasaan shahihah adalah kebiasaan yang diterima orang banyak, sopan santun dan berbudaya luhur. Rasulullah Saw bersabda
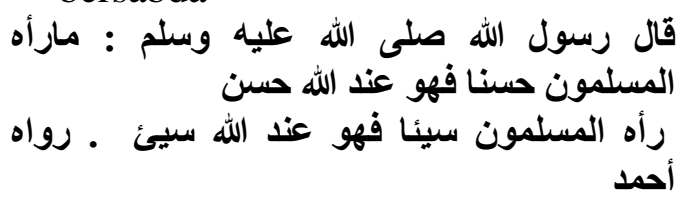

"Semua yang dianggap baik oleh kaum muslimin, maka disisi Allah

23 Sebagaimana firman Allah swt dalam surat An Nisa";23 “ apa yang diharamkan akibat susuan sama dengan yang diharamkan dengan akibat hubungan nasab".

24 Zurifah Nurdin. Disertasi,UIN Raden Intan Lampung, h. 107-123 2018 
juga baik. Dan begitu sebaliknya " HR Ahmad ${ }^{25}$

Kemaslahatan yang dimaksud adalah yang erta hubungannya dengan dengan penjagaan dan keselamatan agama, jiwa, akal, keturunan dan harta. dan yang dimaksud dengan kemaslahatan adalah berbading lurus dengan tujuan syara' walaupun bertentangan dengan tujuan manusia

d. Metode Penelitan

Sedangkan metode penelitian yang digunakan adalah diskriftif kualitatif, Data didapat melalui wawancara dengan tokoh masyarakat, sesepuh, dan alim ulama setempat dan juga menggunakan pengamatan dilapangan. Tokoh masyarakat, sesepuh dan alim ulama yang dipilih sebagai sumber data primer karena mereka ini mempunyai kompetensi untuk menjawab pertanyaanpertanyaan yang penulis utarakan.

\section{Hasil Penelitian dan Pembahasan:}

a. Hasil Penelitian

Berdasarkan hasil wawancara ${ }^{26}$ dan pengamatan, di dapat data bahwa semua semua narasumber menyatakan kalau perempuan yang haram dinikahi untuk selamanya adalah selain ibu, nenek baik kandung ataupun ibu tiri, adik baik kandung maupun tiri, cucu, tiri atau kandung, ponaan baik dari pihak ayah maupun ibu sekandung dan ataupun tiri. Kemudian sepupuh yakni anak bibi dari bapak dan sepupuh anaknya

25 Kitab Hadis 9. Kitab Ahmad.

26 Wawancara dilakukan September 2020 sebanyak 20 orang narasumber, terdiri dari 8 orang tokoh masyarakat, 10 alim ulama dan 2 orang sesepuh paman dari ibu.Namun jika sepupuh anak paman dari ayah dan anak bibik dari ibu halal dinikahi.

Diharamkan menikahi anak bibik dari bapak dan anak paman dari ibu (sepupuh) merupakan perbuatan tabu /cacat moral sebab memanggil ayah pada adik ibu dan memanggil ibu kepada adik bapak, sama halnya dengan menghalalkan dua beradik kandung menika. Memanggil ibu saja kepada adik perempuan ayah dan memanggil ayah kepada adik laki-laki ibu bukan karena menikahi anak mereka hukumnya haram apalagi menikahi anak mereka, yang otomatis akan menjadi orang tuanya dan sudah dipastikan memanggil mertua dengan panggilan ayah atau ibu. Mereka beranggapan bahwa memanggil ibu kepada bibi dari ayah dan memanggil ayah pada paman dari ibu dalam bahasa Lintang dinamai menula (kekurang ajara/sifat tidak terpuji, tercelah). Akan tetapi jika yang dinikahi itu adalah anak paman dari ayah atau anak bibik dari ibu dibolehkan karena memanggil mereka dengan sebutan bapak/ayah serta ibu bukan termasuk perbuatan nula/tercelah.

Jadi menurut penulis alasan kenapa mereka memahami sepupuh anak bibik dari pihak ayah dan paman dari pihak ibu adalah karena kedua orang tua mereka berstatus/mempunyai hubungan kelawai muanai(miani). Muanai/ kakak atau adik laki-laki sedangkan kelawai kakak atau adik perempuan. Muanai tanggungjawabnya sama dengan wali, yakni wajib melindungi kelawainya, tidak etis/ tidak bijak 
meninkahi anak orang yang bertanggungjawab melindungi. perbuatan ini bagaikan pagar makan tanaman.

b. Pembahasan

Pemahaman masyarakat suku Lintang tentang sepupuh yakni anak paman dari ibu dan anak bibik dari ayah haram dinikahi karena menyamakan kedudukan anak paman dari pihak ibu dan anak bibik dari pihak ayah dengan haramnya menikahi dua orang kakak adik kandung, yang mana tanggungjawab nya sama yakni melidungi, sehingga orang yang seharusnya dilindungi tabu untuk dinikahi, dalam arti kata menikahinya merupakan perbuatan tercelah.

Walau pemahaman masyarakat suku Lintang ini bertentangan dengan pemahman para fuqaha sebagaimana dijelaskan dalam kitab-kitab fiqh bahwa menikahi anak bibik dan paman dari pihak ayah ataupun pihak ibu hukumnyah boleh, Namun menurut menurut penulis apa yang dipahami oleh masyarakat suku Lintang tentang pengharaman menikahi anak bibik dari pihak ayah dan anak paman dari pihak ibu jika dilihat dari sudut pandang al' urfu termasuk al; urf ashahihah karena tidak menyalahi maqashid syari'ah khususnya menjaga akal dan jiwa. Dikatagorikan menjaga akal karena tujuan diharamkannya itu untuk tetap menjaga tanggungjawab sebagai wali sebab kedudukan sepupuh laki-laki terhadap sepupuh perempuan sama halnya sebagai wali. Dan menjaga jiwa, agar rasa kasih saying yang terjalin antara suami istri tetap murni bukan terjalin karena adanya hubungan darah. Haram menikahi anak bibik dari ayah dan anak paman dari ibu karena sadd adzari'ah, dalam rangka menghindari terjadinya perpecahan atau permusuhan dalam keluarga dekat jika terjadi perceraian. Dengan demikian jelas bahwa diharamkannya anak bibik dari bapak dan anak paman dari ibu dalam rangka menjunjung tinggi tujuan pernikahan dalam hal memperbanyak sanak family, yang tadinya bukan siapa-siapa dapat menjadi saudara, yang tadinya tidak kenal menjadi kenal dan menjadi saudara, sehingga menjadi keluarga besar. dan seandainya terjadi perceraian antara suami istri ini, tidak menggangu hubungan saudara yang mempunyai hubungan darah.

Dalam Islam Pengharaman menikahi perempuan-perempuan sebagaimana dijelaskan dalam rangka memperkokoh rasa sayang dan cinta yang tulus dan ikhlas dalam keluarga yang bebas dari kepentingan apapun, menghilangkan rasa tamak sehinggga persatuan pergaulan suami istri terwujud dan terbina karena cinta kasih yang murni. Faedah lainnya adalah untuk menghindari renggangnya ataupun terputusnya hubungan kekeluargaan dan silaturahmi antar kedua keluarga jika terjadi kesalah pahaman dalam keluarga yang baru dibinah itu. ${ }^{27}$ Dan untuk mendapatkan keturunan yang kuat secara mental, fisik, spritual dan

27 Wahbah az Zuhaili dalam al Fiqh al Islamy,. Op. Cit., h. 127 
kecerdasan yang tinggi. ${ }^{28}$ Itu artinya haram menikahi anak perempuan bibi (adik perempuan ayah) dan anak perempuan paman(adik laki-laki ibu) sebagaimana yang pemahaman masyarakat suku Lintang dan menurut mereka bertujuan menjaga kehormatan dan martabat tata tertib perwalian pernikahan, dan juga menjaga hubungan baik antara kedua keluarga. sejalan dengan pemahaman yang diinformasikan dalam fiqh.

Menurut teori al" urf jika suatu perbuatan jika penetapan hukumnya tidak bertentangan dengan lima hal pokok yakni menjaga agama, akal, jiwa, keturunan dan harta (Maslahah Mursalahah Adhoruriyah), maka perbuatan itu, dalam kontek ini adalah haram menikahi anak perempuan bibik dari ayah dan anak perempuan paman dari ibu sebagaimana yang terjadi pada masyarakat Lintang termasuk dalam ur'f shohihah, sehingga seide dengan kaidah العادة محكمة adat yang demikian ini dapat dijadikan sebagai sandaran hukum. Pengahraman menikahi anak perempuan bibik dari ayah dan anak perempuan paman dari ibu sebagaimana pada masyarakat Lintang sesuai dengan metode istinbat hukum Sadd Al-dzari'ah, yang dipertimbangkan adalah akibat yang ditimbulkan jika terjadi pertengkaran dalam keluarga. Pengharaman ini sesuai dengan kaidah ini

28 dalam salah satu Atsar disebutkan bahwa menikahi seseorang yang ada hubungan dara harus dihindari agar terhindar dari mendapatkan keturunan yang cacat.

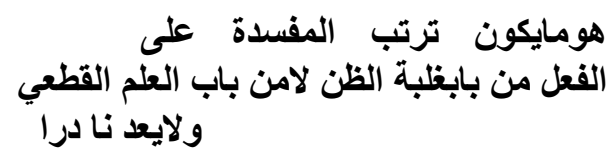

Perbuatan yang kadar kemungkinan terjadinya kemafsadatan tergolong dalam katagori persangkaan kuat, tidak sampai pada katagori yakin , tidak pula terhitung jarang. Hal ini didasarkan pada sangkaan kuat yang disamakan dengan keyakinan pasti sebab sadd adzaria'ah (penutup perantara) mengahruskan kehati-hatian untuk meminimalisir dugaan kuat terjadinyai kemafsadatan.

\section{Kesimpulan:}

Dalam lteratur kitab-kitab Fiqh menikahi sepupuh baik anak perempuan paman dan bibik dari pihak ibu maupun pihak ayah itu diperbolehkan, Sedangkan dalam pemahaman masyarakat suku Lintang haram menikahi sepupuh khusus anak perempuan yang lahir dari bibik dari pihak ayah dan anak paman dari pihak ibu, dan untuk sepupuh yang lahir dari bibik dari ibu dan atau anak paman dari pihak ayah menikahinya boleh. Tujuan pengharaman menikahi sepupuh ini dalam rangka menghormati dan menjunjung tinggi martabat posisi wali dalam system kekerabatan patrilineal yang mereka anut. Menurut penulis pengharaman ini karena Sadd Aldzari'ah, menutup terjadinya kemudharatan yang besar jika timbul pertengkaran dalam rumah tangga

Jika anak bibi dari ayah dan anak paman dari ibu boleh dinikahi, maka kemudharatan besar yang terjadinya saat pertengkaran dalam rumah tangga terjadi dan apalagi berakhir perceraian adalah adanya permusuhan yang berkepanjangan, 
hubungan keluarga besar menjadi terbelah dan ini jelas menyalahi tujuan terjadinya pernikahan.

\section{REFERENSI:}

Ahmad Zainul Wafa AL-HUKAMA The Indonesian Journal of Islamic Family Law 2011; . http://etheses.uinmalang.ac.id/1690/6/0321003 7

Al- Shiddieq,Tengku Muhammad Hasbi"Fiqhul Sunnah" Tth.

Al- Shiddieq,Tengku Muhammad Hasbi"Fiqhul Sunnah" Tth.

Al-Asyqalãnī Ibn Hajar, Bulữgh alMarãm min Adillat al-Ahkam, t.tp: Dãr al- Kut b Islamiyah, t. th

Al-Duraini, Fathin, al-Manãhij alUsuliyyah bi al-Ra'yi $\mathrm{f} \bar{l}$ alTasyri', Damasyik: Dar al Kutub al Hadist, 1975

Al-Habsyi, Muhammad Bagir Fiqh Praktis Menurut al-Qur'an, Sunnah, dan Pendapat para Ulama' , Bandung: Mizan, 2002

Al-Zuhaili Wahbah"al Fiqh al-Islamy Wa Adilatuhu"diterjemahkan oleh Darul Fikri, Gema Insani jilid 9 Jakarta.
Aulawi, Asro Sastroatmodjo dan A. Wasit, Hukum Perkawinan di Indonesia, Jakarta; Bulan Bintang, 1975

Djazuli, Kaida-Kaidah Fikih, Kaidahkaidah Hukum Islam dalam Menyelesaikan MasalahMasalah yang Praktis, Jakarta, Kencana Prenada Media Group, 2011

Haroen, Nasrun, Ushul Fiqh I, Jakarta: Logos Wacana Ilmu, 1977,.

Rahendra Maya, wanita-wanita-yangdilarang-dinikahi.html Syaikh Abdullah bin Abdurrahman bin Shalih Ali Bassam jurnal.staialhidayahbogor.ac.id Desember. https://almanhaj.or.id/1741

Rusdy, Ibnu, Bidayatu al- Mujtahid Analisis Para Mujtahid judul asli Bidayatul Mujtahid wa Nihayatul Muqtashid, diterjemahkan oleh Imam Ghazali Said dan Ahmad Zaidun, Jakarta; Pustaka Amani, 2007

Zurifah Nurdin, Etika Mencari Pendamping Hidup Menurut

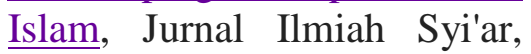
2017,

https://ejournal.iainbengkulu.a c.id/index.php/syiar/article/vie w/910. 


\section{Lampiran}

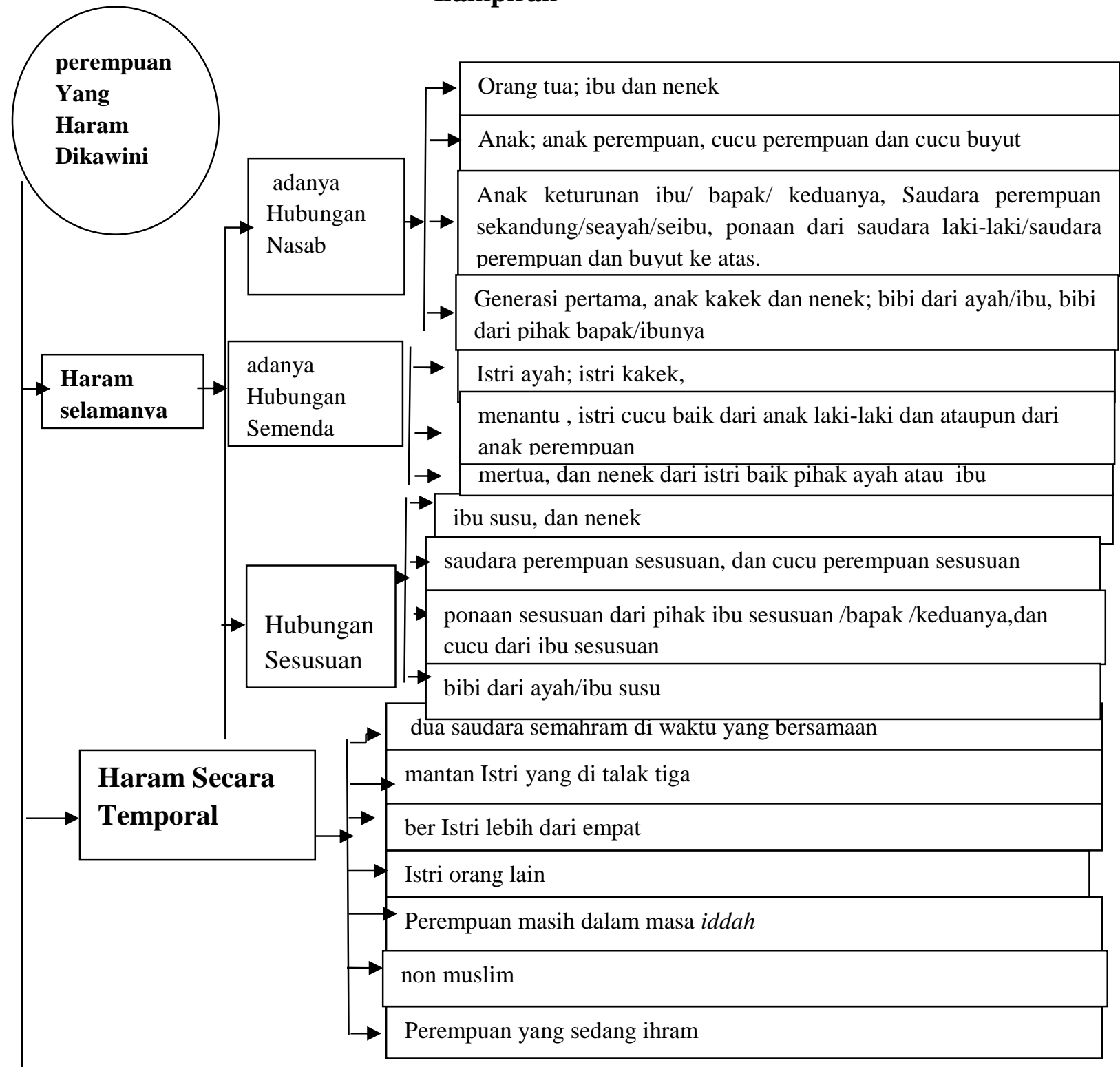

